\title{
Results of an Opioid Hazard Awareness Training Intervention for Stone, Sand, and Gravel Miners
}

\author{
Cora Roelofs ${ }^{1} \mathbb{D}$
}

Received: 11 March 2021 / Accepted: 27 October 2021 / Published online: 19 November 2021

(C) The Author(s) 2021

\begin{abstract}
In the USA, miners are at higher risk for work-related disorders that could precipitate an opioid prescription, injury-related opioid prescriptions, and opioid overdose. We aimed to support prevention of these outcomes with an "opioid hazard awareness" miner safety training module. In January and February 2020, the training module was embedded within required mining safety and health training for stone, sand, and gravel miners in Massachusetts (USA). Training impact and reception were assessed with a pre- and post-training survey of trainee characteristics, training content knowledge, and attitudes. Over 800 miners were trained and over 600 responded to surveys. We found statistically significant improvements in opioid risk factor knowledge and knowledge of resources to help a coworker. Nonstigmatizing attitudes were high both at baseline and following the training. The training was perceived as relevant and useful by trainees. Improving opioid hazard awareness in high-risk worker populations has potential to reduce opioid dependence and downstream impacts including overdose death. Employer injury-prevention efforts should be reinforced while worker health and safety training enhances awareness of opioid-related harms and prevention strategies for miners and other high-risk worker populations.
\end{abstract}

Keywords Analgesics, Opioid · Miners · Training

\section{Introduction}

Since the beginnings of the opioid epidemic in 1999, almost 450,000 people have died from opioid-related overdoses in the USA [1]. Miners are in the highest risk occupational group for prescription opioid overdose and have the greatest likelihood of receiving opioids for work-related injury [2,3]. The Massachusetts's Department of Public Health's analysis of occupation and industry reported on the death certificates of people who had died of opioid overdose found that workers in the construction and extraction occupation had a death rate seven times that for all workers [4].

Investigators have identified injuries in the workplace as a factor in the rise of opioid dependence and opioid-related deaths, despite relatively flat injury rates [5-8]. The increase in opioid-related deaths has, until recently, closely tracked

Cora Roelofs

cora_roelofs@uml.edu

1 Department of Biomedical Engineering, Center for the Promotion of Health in the New England Workplace, University of Massachusetts Lowell, 1 University Avenue, Lowell, MA 01854, USA with the significant rise in opioid prescriptions for pain, including work-related pain $[9,10]$. Documented workplace risk factors for musculoskeletal pain include physically- and psychosocially demanding work, repetitive tasks, awkward postures, and slips, trips, and falls-all of which are potential hazards in mining operations [11]. Increased age, obesity, smoking, and depressive symptoms have also been identified as risk factors for work and non-work-related low back pain which is commonly treated with opioids [12].

Workers may be prescribed opioids to allow them to continue working and to return to work following an injury or surgery, despite the safety risks of using narcotics while operating equipment [13-15]. Use of opioids for workrelated injuries is also linked to long-term disability which may, in turn, add to the risk of opioid use disorder [16-18]. Clinical practice guidelines advise against routine use of opioids for work-related chronic pain due to their potential harm outweighing their benefits; however, high-dose and long-term opioids continue to be prescribed to workers experiencing pain and injuries [19-22]. Policy responses have included interventions to reduce opioid prescribing and to "screen out" substance users from employment via workplace drug testing [23, 24]. 
Mining safety and health rules require that all those who work in mining operations receive annual health and safety training that targets key risk factors for injuries and illnesses. However, there is currently no requirement for training on drugs and alcohol in mining (a proposed rule that would have required such training was withdrawn) [25]. This study describes an intervention aimed at reducing opioid harms in the stone, sand, and gravel mining sector-the largest mining sector in the USA in terms of the number of operations and employees [26].

\section{Materials and Methods}

\subsection{Intervention and Participants}

To address the opioid health hazard disparities faced by miners, we developed a short training to enhance knowledge of the opioid crisis, awareness of the potential hazards associated with opioids, and the work-related factors that could lead to a prescription and/or opioid use disorder and overdose. We refer to this as "opioid hazard awareness." The objectives of the training module were to improve knowledge about opioids, reinforce positive attitudes, and encourage skills that could empower trainees to take action for themselves and others in the worksite, doctors' offices, and communities to reduce potential harms related to opioids.

The 30-min opioid hazard awareness training module was tailored to Massachusetts stone, sand, and gravel workers and designed for inclusion in annual U.S. Mining Safety and Health Administration (MSHA) refresher training that is required for all miners and others, such as contractors, who enter mine property. Day-long refresher training is offered by mine operators and by the Massachusetts Department of Labor Standards (MA DLS) across the Commonwealth in January and February each year to over 800 participants- $80 \%$ of the target workforce. Massachusetts was selected for geographical convenience; however, the state has been hard-hit by the opioid epidemic: the 2018 ageadjusted death rate from opioids was 29.3/100,000 in Massachusetts compared to the US rate of 14.6/100,000 [27].

The training presentation was developed from discussion with mine safety trainers and mine operators and from previously developed trainings for construction workers and others $[28,29]$. The training content included recognizing which medications are opioids, work-related risk factors for opioid use, prevention strategies such as ergonomics and tips for the doctor's office, and "harm reduction" approaches such as avoiding stigmatizing attitudes that discourage helpseeking and preventing fatal overdoses through the use of naloxone. The training concluded with resources for helping someone struggling with substance issues. The training outline is described in Fig. 1. Figure 2 is an example of a training slide. While the time available for discussion was quite short, one slide encouraged trainees to think about questions such as "Should doctors be able to say someone is 'fit for duty' if they are taking opioids?" Training materials were reviewed by experts in mine safety, trainers, and mine operators and revised according to their recommendations.

In addition to the slide presentation, an instructors' guide was developed to add interactive elements, clarify slide content, and relay training procedures including administration of the pre- and post-training surveys. A participants' guide was also developed and inserted into the MA DLS Refresher Training "Book" for all participants. "Train-the-trainer" sessions were held to train the two trainers who had been hired to deliver the training during the MA DLS-scheduled MSHA refresher trainings. One consultant trainer began his career as a sand and gravel miner and eventually retired from the position of safety director in this industry. Both had immediate family members who had been impacted by the opioid epidemic. Additional trainers included the investigator,

Fig. 1 Training module outline

1. Overview

2. Opioid Crisis $=a$ Public Health Crisis

3. The Changing Crisis

4. Miners at Risk

5. Opioid Hazard Risk Factors

6. What's an opioid?

7. Side Effects

8. Safety Risks: Opioids at Work

9. Who gets addicted?

10. Addiction is a Disease

11. Opioids Hijack the Brain

12. Addiction Pathway

13. Prevention and Harm Reduction
14. LEVEL 1: Prevent the Causes of Pain

15. LEVEL 2: Avoid Exposure to Opioids

16. LEVEL 2: Advocate for Yourself

17 . What about my pain?

18. Questions: Opioids and Safety-Sensitive Work

19. Impaired on the job: What to do?

20. LEVEL 3: Substance Use Disorder Treatment

21. LEVEL 3: Reduce the Harms of Stigma

22. LEVEL 3: Reduce the Harms of Opioid Addiction

23. Common Challenges-Beyond Opioids

24. Total Worker Health - Dimensions of Wellness

25. Resources 
Fig. 2 Training slide example

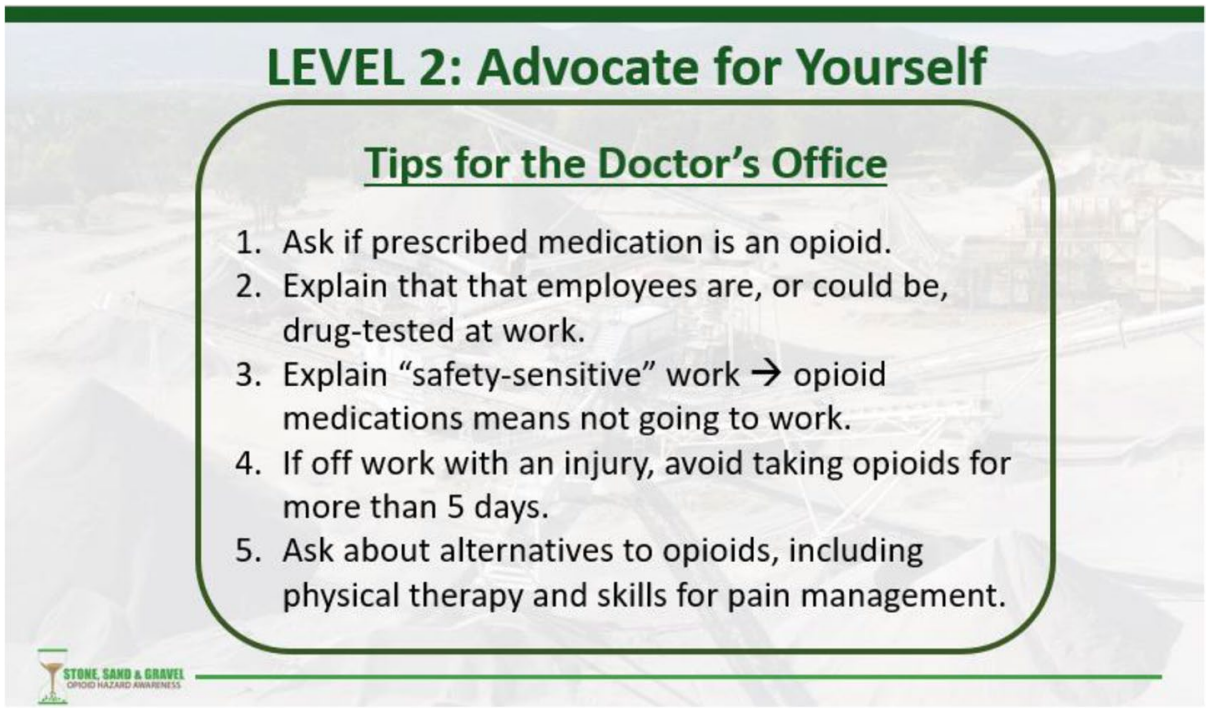

company health and safety directors, a consultant trainer, and the staff of the MA DLS MSHA training program.

\subsection{Instrument}

Brief pre- and post-training surveys were administered to all participants on paper immediately preceding and after the training. The pre-training survey included basic demographic and trainee characteristics questions including if they held a Commercial Drivers' License (CDL), their age, and their experience with injuries and opioids, such as having experienced physical pain related to work that lasted 1 week or more in the past 12 months. These questions related to risk and protection factors for opioid use. For example, older workers have greater risk of musculoskeletal pain. Workers with CDL would be subject to drug testing and would not be permitted to drive while taking opioids according to federal Department of Transportation rules. Eight multiple choice and true/false questions related to opioid hazard knowledge and attitudes were included on both the pre-training and the post-training survey. The post-training survey also included four questions related to training quality and space for comments. Questions were drawn from the training content, interpretation of questions to assess stigma, and prior surveys used by the investigator [30]. Surveys were anonymous and therefore unmatched from pre- to post-training. Human subject participation and procedures were approved by the University of Massachusetts Institutional Review Board (\#19-100-EXP dated 7/12/19).

\subsection{Analysis}

Surveys were entered manually into Qualtrics ${ }^{\mathrm{TM}}$ by a research assistant with quality checks by the investigator. Response frequencies and means were calculated, along with pre- to post-training changes (expressed as the difference of response frequencies as a percent of the pre-survey value). Chi-squared tests of associations between respondent characteristics and survey responses were also conducted.

\section{Results}

\subsection{Participant Characteristics}

The opioid hazard awareness training for stone, sand, and gravel workers module was used in 20 MSHA refresher training days in January and February 2020 in Massachusetts. At least 800 workers were trained. For the 14 trainings that were sponsored by MA DLS under an MSHA Training Grant, project trainers conducted the training and administered the pre- and post-training surveys to the $762 \mathrm{~min}$ ers and others who attended the trainings. A total of 598 pre-surveys and 623 post-surveys were returned, for participation of $78 \%$ and $82 \%$, respectively. For the remaining "private" trainings, operators, their consultants, or MA DLS staff conducted the trainings and used our module, but did not administer surveys.

One-third of the respondents reported their job title as "miner", and another third reported their title as "other" including laborer, driller, welder, or supervisor-essentially mining job titles. The remaining third consisted of maintenance, multiple titles, and truck drivers. The age of respondents ranged from 18 to $76($ mean $=45)$ and was somewhat older on average than the general working age population: $55 \%$ were 45 years old or older [31]. Sixty-five percent of the respondents had more than 10 years' experience in their job or a similar one. More than $40 \%$ of respondents had CDLs. Thirty percent $(n=175)$ reported having had work-related pain in the past year, and 7\% $(n=44)$ had received an opioid 
prescription for work-related pain. Reporting work-related pain was associated with reporting having received prescription opioids from a licensed provider $(p<0.01)$.

\subsection{Pre- to Post-Training Changes in Knowledge and Attitudes}

Table 1 shows pre- and post-training survey responses and group-level changes. Reporting good or very good knowledge about opioid side effects increased from 71 to $91 \%$ $(p<0.01)$. Additionally, affirmative responses to the question regarding knowledge of resources to help a co-worker struggling with substance issues increased from 67 to $88 \%$ $(p<0.01)$. There were no statistically significant changes in comfort in discussing opioid issues, either with a doctor or a co-worker, nor in response to questions regarding stigma. For these questions, responses were in line with positive attributes (high comfort, confidence, and nonstigma) both pre- and post-training.

We analyzed subgroup differences between CDL holders versus those without CDLs and by age. Largely, there were no differences in responses; however, CDL holders were more likely to answer "true" to the question about whether addiction can happen to anyone (an indicator of not holding stigmatizing attitudes) than those without a CDL $(p<0.01)$. Those under age 50 were more likely to report good or very good knowledge of side effects $(p<0.03)$ both pre- and post-training.

Table 1 Opioid hazard awareness pre- and post-training responses, Massachusetts 2020

\begin{tabular}{|c|c|c|c|c|c|}
\hline \multirow[b]{2}{*}{ How would you rate your knowledge about the side effects of opioid-based pain medications? } & \multicolumn{2}{|c|}{$\begin{array}{l}\text { Pre- } \\
\text { training }\end{array}$} & \multicolumn{2}{|c|}{$\begin{array}{l}\text { Post- } \\
\text { training }\end{array}$} & \multirow[t]{2}{*}{ Change' } \\
\hline & $n=$ & 590 & $n=$ & 619 & \\
\hline Very good knowledge & 138 & $23 \%$ & 242 & $39 \%$ & $67 \%$ \\
\hline Good knowledge & 325 & $55 \%$ & 321 & $52 \%$ & $-6 \%$ \\
\hline Poor knowledge & 92 & $16 \%$ & 42 & $7 \%$ & $-56 \%$ \\
\hline Very poor knowledge & 35 & $6 \%$ & 14 & $2 \%$ & $-62 \%$ \\
\hline Opioids work by reducing the causes of pain in the body & $n=$ & 575 & $n=$ & 613 & \\
\hline True & 333 & $58 \%$ & 239 & $39 \%$ & $-33 \%$ \\
\hline False & 242 & $42 \%$ & 374 & $61 \%$ & $45 \%$ \\
\hline Opioid addiction can happen to anyone & $n=$ & 594 & $n=$ & 616 & \\
\hline True & 573 & $96 \%$ & 592 & $96 \%$ & $0 \%$ \\
\hline False & 21 & $4 \%$ & 24 & $4 \%$ & $10 \%$ \\
\hline People with opioid addiction can never recover & $n=$ & 585 & $n=$ & 614 & \\
\hline True & 32 & $5 \%$ & 33 & $5 \%$ & $-2 \%$ \\
\hline False & 553 & $95 \%$ & 581 & $95 \%$ & $0 \%$ \\
\hline $\begin{array}{l}\text { If a doctor gives you a prescription for opioid-based pain medication, you know that it's safe to take while } \\
\text { working }\end{array}$ & $n=$ & 576 & $n=$ & 614 & \\
\hline True & 33 & $6 \%$ & 40 & $7 \%$ & $14 \%$ \\
\hline False & 543 & $94 \%$ & 574 & $93 \%$ & $-1 \%$ \\
\hline How confident would you feel talking to a doctor about safety concerns of opioids? & $n=$ & 583 & $n=$ & 613 & \\
\hline Very high confidence & 267 & $46 \%$ & 297 & $48 \%$ & $6 \%$ \\
\hline High confidence & 263 & $45 \%$ & 249 & $41 \%$ & $-10 \%$ \\
\hline Low confidence & 39 & $7 \%$ & 47 & $8 \%$ & $15 \%$ \\
\hline Very low confidence & 14 & $2 \%$ & 20 & $3 \%$ & $36 \%$ \\
\hline How comfortable would you feel talking to a co-worker about your own use of opioids? & $n=$ & 562 & $n=$ & 602 & \\
\hline Very high level of comfort & 189 & $34 \%$ & 208 & $35 \%$ & $3 \%$ \\
\hline High level of comfort & 187 & $33 \%$ & 219 & $36 \%$ & $9 \%$ \\
\hline Low level of comfort & 95 & $17 \%$ & 106 & $18 \%$ & $4 \%$ \\
\hline Very low level of comfort & 91 & $16 \%$ & 69 & $11 \%$ & $-29 \%$ \\
\hline $\begin{array}{l}\text { If a co-worker asked you about where to get help for someone struggling with opioids, do you know at least } \\
\text { one good resource you could refer them to? }\end{array}$ & $n=$ & 587 & $n=$ & 616 & \\
\hline Yes & 396 & $67 \%$ & 541 & $88 \%$ & $30 \%$ \\
\hline No & 191 & $33 \%$ & 75 & $12 \%$ & $-63 \%$ \\
\hline
\end{tabular}

*Difference in proportion from pre- to post-training. Chi-squared tests evaluated statistical significance of changes and are described in the text 


\subsection{Training Evaluation}

Overall, trainees found the training useful and relevant (Table 2). Ninety-four percent would recommend the training. Many of the voluntary written comments were also positive; a few questioned whether the training related to miner safety, or they disagreed with the view that addiction was a disease (which was included in the training's discussion of substance use disorder). In the interviews, trainers expressed satisfaction with their preparation to provide the training and regarded the training experience as positive.

\section{Discussion}

The purpose of this study was to trial an opioid hazard awareness training module in the stone, sand, and gravel sector with the goal of improving miner knowledge, attitudes, and skills related to opioids. Following state-wide delivery to at least 800 surface mining workers, the training increased knowledge about opioids and was positively received by the trainees. The program had little impact on attitudes, likely because this trainee population of stone, sand, and gravel workers already had a high degree of positive, non-stigmatizing attitudes. Our two "stigma" questions failed to detect strong biased views in the pre-survey. The question that was used to detect a mix of "attitude" and "skills" showed that the training helped increase comfort about potentially talking to a co-worker about your own opioid use. Perhaps most significantly, respondents' perspective that they could provide a co-worker with a good resource if they were struggling with opioids increased by $30 \%$. Thus, this short training likely increased respondents' knowledge,

Table 2 Opioid hazard awareness training evaluation, Massachusetts 2020

\begin{tabular}{|c|c|c|}
\hline $\begin{array}{l}\text { Training increased my awareness of the hazards of } \\
\text { opioids }\end{array}$ & $n=614$ & \\
\hline Strongly agree/agree & 531 & $86 \%$ \\
\hline Disagree/strongly disagree & 83 & $14 \%$ \\
\hline $\begin{array}{l}\text { The training helped me understand what can be done } \\
\text { to prevent opioid addiction }\end{array}$ & $n=606$ & \\
\hline Strongly agree/agree & 546 & $90 \%$ \\
\hline Disagree/strongly disagree & 60 & $10 \%$ \\
\hline $\begin{array}{l}\text { I can apply what I learned in this training to protect } \\
\text { myself and others from opioid hazards }\end{array}$ & $n=605$ & \\
\hline Strongly agree/agree & 557 & $92 \%$ \\
\hline Disagree/strongly disagree & 48 & $8 \%$ \\
\hline I would recommend this training & $n=604$ & \\
\hline Strongly agree/agree & 557 & $92 \%$ \\
\hline Disagree/strongly disagree & 48 & $8 \%$ \\
\hline
\end{tabular}

ability, and willingness to recognize opioid hazards, take preventive action, and provide assistance to others.

To our knowledge, this is the first evaluated training aimed at the prevention of opioid harms in the mining sector. However, the training under study here closely models the aims of worker opioid awareness training developed for other high-risk sectors [28, 32]. Our results align with those of a recent evaluation of a longer-format opioid hazards prevention training developed for the National Institute of Environmental Health Sciences Worker Training Program and with the results reported from a training program for workers in construction, nursing, and material moving occupations $[29,33]$.

The training was relatively short and was able to be adapted to an existing training infrastructure. We were able to prepare several trainers-none with background in substance use education - to deliver the training and supported these trainers with a trainer's instruction manual and participant handout. Additional strengths of this study include the reach of the training (approximately $80 \%$ of the workforce in Massachusetts), a very high response rate to the survey, and the intervention's adaptability beyond Massachusetts. The module has been revised for a national audience and is available as an on-line fully narrated version and for virtual delivery or in person by mining safety trainers. (All training materials including the slides, trainers' guide, and survey are freely available by contacting the author-see https://www. uml.edu/Research/CPH-NEW/education-training/OpioidHazard-Awareness/). The revised training includes a posttraining survey that aligns with the one used in this study.

Limitations include the use of a training assessment instrument that has not been validated and the lack of outcomes data that could relate a reduction in opioid-related harms to the impact of the training. We did not match responses on pre- and post-training surveys and cannot conclude that the population changes that we observed correspond to within trainee changes. Overall, changes were modest as would be expected with such a low-intensity training. Additionally, we did not assess the impact of the training on the workplace or worker behavior. A follow-up survey was attempted by phone 4 months post-training, but failed to generate a sufficient number of responses (18) to describe the results here.

\section{Conclusions}

Pervasive prescription and non-prescription opioids continue to have a devasting public health impact. Opioid overdose deaths have been identified as a leading cause of death and contributor to a decline in life expectancy in the USA. In addition to avoidable deaths, opioid use and dependency have led to an epidemic of substance use 
disorder and extreme suffering among those afflicted, their families, and communities. Opioid overdose prevention efforts, such as proliferation of naloxone overdose anaphylaxis, provider education, and prescribing policy changes, have had some impacts in reversing the deadly toll. However, greater attention to upstream prevention efforts aimed at promoting understanding of and action on the causes of opioid use in high-risk populations is needed. Employers can take a variety of actions, including deploying the training described here, as well as reducing site hazards that can lead to painful injuries, monitoring prescription drug benefits for high opioid prescribing, and facilitating access to substance use treatment [8]. This study provides evidence that even a brief educational intervention, targeted to the needs and interests of a high-risk worker population, can help promote knowledge and attitudes to prevent opioid harms before they begin. Future research will include expanding the training to other mining sectors and evaluating the impact of training and other organizational interventions on mine operations, worker actions, and reductions in opioid-related harms.

Acknowledgements The author wishes to thank Dr. Rebecca Gore for her assistance with the analyses; Drs. Gore, William Shaw, and Laura Punnett for comments on the manuscript; Abbas Kazi for assistance with data entry; the Massachusetts Department of Labor Standards; the Massachusetts Coalition for Occupational Safety and Health; and the project trainers.

Funding This study was funded by the Alpha Foundation for the Improvement of Mine Safety and Health, Inc. Grant No. AFC820-14. This study was sponsored by the Alpha Foundation for the Improvement of Mine Safety and Health, Inc. Grant No. AFC820-14.

\section{Declarations}

Ethical approval All procedures performed in studies involving human participants were in accordance with the ethical standards of the University of Massachusetts Institutional Review Board and with the 1964 Helsinki declaration and its later amendments or comparable ethical standards. This article does not contain any studies with animals. Human subject participation and procedures were approved by the University of Massachusetts Institutional Review Board (\#19-100EXP dated 7/12/19).

Informed consent Informed consent was obtained from all individual participants included in the study.

Conflict of interest Informed consent was obtained from all individual participants included in the study.

Disclaimer This study was sponsored by the Alpha Foundation for the Improvement of Mine Safety and Health, Inc. The views, opinions, and recommendations expressed herein are solely those of the author and do not imply any endorsement by the Alpha Foundation, its Directors, and staff.
Open Access This article is licensed under a Creative Commons Attribution 4.0 International License, which permits use, sharing, adaptation, distribution and reproduction in any medium or format, as long as you give appropriate credit to the original author(s) and the source, provide a link to the Creative Commons licence, and indicate if changes were made. The images or other third party material in this article are included in the article's Creative Commons licence, unless indicated otherwise in a credit line to the material. If material is not included in the article's Creative Commons licence and your intended use is not permitted by statutory regulation or exceeds the permitted use, you will need to obtain permission directly from the copyright holder. To view a copy of this licence, visit http://creativecommons.org/licenses/by/4.0/.

\section{References}

1. CDC Injury Center. Opioid data analysis and resources 2021. https://www.cdc.gov/drugoverdose/data/analysis.html (accessed 16 Feb 2021)

2. Harduar Morano L (2018) Occupational patterns in unintentional and undetermined drug-involved and opioid-involved overdose deaths - United States, 2007-2012. MMWR Morb Mortal Wkly Rep 67. https://doi.org/10.15585/mmwr.mm673 $3 \mathrm{a} 3$.

3. Thumula V, Liu T-C (2018) Correlates of opioid dispensing. WC-18-48. Workers Compensation Research Institute, Cambridge, MA.

4. Hawkins D, Roelofs C, Laing J, Davis L (2019) Opioid-related overdose deaths by industry and occupation-Massachusetts, 2011-2015. Am J Ind Med 62:815-825. https://doi.org/10.1002/ ajim.23029

5. Choi B (2020) Opioid use disorder, job strain, and high physical job demands in US workers. Int Arch Occup Environ Health 93:577-588. https://doi.org/10.1007/s00420-019-01514-4

6. Kowalski-McGraw M, Green-McKenzie J, Pandalai SP, Schulte PA (2017) Characterizing the interrelationships of prescription opioid and benzodiazepine drugs with worker health and workplace hazards. J Occup Environ Med 59:1114-1126

7. Cheng M, Sauer B, Johnson E, Porucznik C, Hegmann K (2013) Comparison of opioid-related deaths by work-related injury. Am J Ind Med 56:308-316. https://doi.org/10.1002/ajim.22138

8. Shaw WS, Roelofs C, Punnett L (2020) Work environment factors and prevention of opioid-related deaths. Am J Public Health 110:1235-1241. https://doi.org/10.2105/AJPH.2020.305716

9. Centers for Disease Control and Prevention (2019) Annual surveillance report of drug-related risks and outcomes - United States Surveillance Special Report. U.S. Department of Health and Human Services. Published November 1, 2019 (accessed 17 Nov 2021 from https://www.cdc.gov/drugoverdose/pdf/pubs/ 2019-cdc-drug-surveillancereport.pdf)

10. Kolodny A, Courtwright DT, Hwang CS, Kreiner P, Eadie JL, Clark TW et al (2015) The prescription opioid and heroin crisis: a public health approach to an epidemic of addiction. Annu Rev Public Health 36:559-574. https://doi.org/10.1146/annur ev-publhealth-031914-122957

11. da Costa BR, Vieira ER (2010) Risk factors for work-related musculoskeletal disorders: a systematic review of recent longitudinal studies. Am J Ind Med 53:285-323. https://doi.org/10. 1002/ajim. 20750

12. Maher C, Underwood M, Buchbinder R (2017) Non-specific low back pain. Lancet 389:736-747. https://doi.org/10.1016/ S0140-6736(16)30970-9

13. Franklin G, Sabel J, Jones CM, Mai J, Baumgartner C, BantaGreen CJ et al (2015) A comprehensive approach to address the prescription opioid epidemic in Washington state: milestones 
and lessons learned. Am J Public Health 105:463-469. https:// doi.org/10.2105/AJPH.2014.302367

14. Pensa MA, Galusha DH, Cantley LF (2018) Patterns of opioid prescribing and predictors of chronic opioid use in an industrial cohort, 2003 to 2013. J Occup Environ Med 60:457-61. https:// doi.org/10.1097/JOM.0000000000001231

15. Dembe A, Wickizer T, Sieck C, Partridge J, Balchick R (2012) Opioid use and dosing in the workers' compensation setting. A comparative review and new data from Ohio. Am J Ind Med 55:313-24. https://doi.org/10.1002/ajim.21021

16. Carnide N, Hogg-Johnson S, Côté P, Irvin E, Van Eerd D, Koehoorn M et al (2016) Early prescription opioid use for musculoskeletal disorders and work outcomes: a systematic review of the literature. Clin J Pain. https://doi.org/10.1097/AJP.00000 00000000452

17. Franklin GM, Stover BD, Turner JA, Fulton-Kehoe D, Wickizer TM, Disability risk identification Study Cohort (2008) Early opioid prescription and subsequent disability among workers with back injuries: the disability risk identification study cohort. Spine 33:199-204. https://doi.org/10.1097/BRS.0b013e3181 $60455 \mathrm{c}$

18. Webster BS, Verma SK, Gatchel RJ (2007) Relationship between early opioid prescribing for acute occupational low back pain and disability duration, medical costs, subsequent surgery and late opioid use. Spine 32:2127-2132. https://doi.org/10.1097/BRS. 0b013e318145a731

19. Buttorff C, Trujillo AJ, Castillo R, Vecino-Ortiz AI, Anderson GF (2017) The impact of practice guidelines on opioid utilization for injured workers. Am J Ind Med 60:1023-1030. https://doi.org/10. 1002/ajim. 22779

20. Mai J, Franklin G, Tauben D (2015) Guideline for prescribing opioids to treat pain in injured workers. Phys Med Rehabil Clin N Am 26:453-465. https://doi.org/10.1016/j.pmr.2015.04.005

21. ACOEM Task Force on the Use of Opioids (2016) Principles for ensuring the safe management of pain medication prescriptions by occupational and environmental physicians (accessed 17 Nov 2021 from https://acoem.org/Guidance-and-Position-Statements/ Guidance-and-Position-Statements/Principles-for-Ensuring-theSafe-Management-of-Pain-Medication-Prescriptions-by-Occup ational-and-Env)

22. Thumula V, Liu T-C, Wang D (2020) WCRI FlashReport-interstate variation and trends in workers' compensation drug payments: 2016Q1 to 2019Q1 FR-20-01

23. Virginia division of mines. Coal mining - substance abuse n.d. https://www.dmme.virginia.gov/dm/SubstanceAbuse.shtml (accessed 28 Feb 2019)
24. Sears JM, Haight JR, Fulton-Kehoe D, Wickizer TM, Mai J, Franklin GM. Changes in early high-risk opioid prescribing practices after policy interventions in Washington State. Health Services Research. https://doi.org/10.1111/1475-6773.13564

25. MSHA proposes drug, alcohol rule for mines. EHS Today 2008. https://www.ehstoday.com/standards/MSHA/msha_drug_alcohol_ mines (accessed 1 Mar 2019)

26. NIOSH. Mine operator and independent contractor employees by sector, 2019 n.d. https://wwwn.cdc.gov/NIOSH-Mining/MMWC/ Employee/Count (accessed 16 Feb 2021)

27. Wilson N (2020) Drug and Opioid-Involved Overdose Deaths United States, 2017-2018. MMWR Morb Mortal Wkly Rep 69. https://doi.org/10.15585/mmwr.mm6911a4

28. CPWR - the Center for Construction Research and Training. Opioid Awareness Training Program n.d. (accessed 17 Nov 2021 from https://www.cpwr.com/research/research-to-practice-r2p/r2p-libra ry/other-resources-for-stakeholders/mental-health-addiction/opioid-resources/opioid-awareness-training-program/)

29. Roelofs C, Sugerman-Brozan J, Kurowski A, Russell L, Punnett L (2021) Promoting opioid awareness through a union-based peer training model. New Solut. https://doi.org/10.1177/1048291120 982597

30. Yang LH, Grivel MM, Anderson B, Bailey GL, Opler M, Wong LY et al (2019) A new brief opioid stigma scale to assess perceived public attitudes and internalized stigma: evidence for construct validity. J Subst Abuse Treat 99:44-51. https://doi.org/10. 1016/j.jsat.2019.01.005

31. U.S. Bureau of Labor Statistics. Employed persons by detailed occupation and age, 2019 n.d. https://www.bls.gov/cps/aa2019/ cpsaat11b.htm (accessed 11 Feb 2021)

32. Roelofs C, Rodman C, Rinehart R, Cain CT (2021) Preventing opioid-related harms in the construction industry: NEW SOLUTIONS: A Journal of Environmental and Occupational. Health Policy. https://doi.org/10.1177/10482911211008174

33. Persaud E, Afable A, Geer LA, Landsbergis P (2021) Opioids and the workplace prevention and response awareness training: mixed methods follow-up evaluation. New Solut:10482911211010344. https://doi.org/10.1177/10482911211010343

Publisher's Note Springer Nature remains neutral with regard to jurisdictional claims in published maps and institutional affiliations. 